\title{
Fabrication and Characterization of Iron Oxide Filled Polyvinyl Pyrrolidone Nanocomposites
}

\author{
T. Agarwal ${ }^{1}$, K. A. Gupta ${ }^{2}$, S. Alam ${ }^{3}$, M. G. H. Zaidi ${ }^{1, *}$ \\ ${ }^{1}$ Department of Chemistry, G.B.Pant University of Agriculture \& Technology, Pantnagar, Uttarakhand, 263145, India \\ ${ }^{2}$ Department of Chemistry, MJP Rohilkhand University Bareilly, 243001, India \\ ${ }^{3}$ Polymer Division, Defence Materials Stores Research Development and Establishment, G.T. Road, Kanpur, 208013 , India
}

\begin{abstract}
The present work describes the synthesis and properties of nanomagnetic polymer composites (MPCs) comprising iron oxide nanoparticles as a filler and polyvinyl pyrrolidone (PVP) as polymer shell. The iron oxide nanoparticles were synthesized under alkaline medium using iron (II) salt. The nanocomposites were synthesized through free radical polymerization under microwave (MW) irradiation. X-ray diffraction reveals the uniform dispersion of iron oxide nanoparticles into polymer matrix. Furthermore, scanning electron microscopy images ensure the development of polymer shell around the nanomagnetic core. The magnetic behaviour of MPCs was studied through vibration sample magnetometry. The thermal durability of MPCs was assessed through simultaneous thermogravimetric-differential thermal analysis-differential thermogravimetry. With MW power ranging 25 to $100 \mathrm{~W}$, the polymerization reactions were progressed resulting in MPCs with improved yield over neat PVP.
\end{abstract}

Keywords Iron Oxide Nanoparticles, Nanomagnetic Polymer Composites, PVP, Microwave Heating, Spectra, Morphology, Thermal Characterization

\section{Introduction}

Recently, great attention has been drawn towards the synthesis and studies of polymer based nanomagnetic composites as they have become a powerful tool for applications in industry, science, and medicine. In particular, the unique magnetic, catalytic and biocompatible properties of nanomagnetic polymer composites (MPCs) make it attractive for use in a variety of area such as recording materials, catalysts, pigment, printing ink, magnetic resonance imaging, heating mediators and drug carriers in magnetic drug targeting[1-2]. Previously, various strategies based on conventional techniques such as dispersion polymerization[3], suspension[4], atom transfer radical polymerization[5], emulsion[6], and electrospinning[7] etc. have been adopted for the development of well crystalline and stable MPCs. Such methods suffer from difficulty to multistep recovery and isolation of product from the reaction batch. The other drawbacks include the intensive use of toxic organic solvents. Thus, the conventional methods are rather tedious and hazardous to environment in the production of MPCs. Recent attention has been turned to the development of synthetic procedures that are environmentally friendly in order to minimize chemical waste as well as potential safety issues associated

* Corresponding author:

mgh_zaidi@yahoo.com (M.G.H. Zaidi)

Published online at http://journal.sapub.org/cmaterials

Copyright (C) 2012 Scientific \& Academic Publishing. All Rights Reserved with the synthesis and processing of polymers and related nanomagnetic composites. Among these alternatives, MW assisted methods offer faster and cleaner way of polymerization[8-9]. The direct heating of molecules under MW irradiation leads to very fast and homogeneous heating that has resulted in the reduction of side reactions, cleaner products and higher yields through rapid energy transfer and high energy efficiency[10-12].

Poly vinyl pyrrolidone (PVP) provides numerous potential biomedical and packaging applications as it is reactive, inexpensive, nontoxic, hydrophilic and biocompatible[13]. However, nanomagnetic polymer composites (MPCs) derived from PVP and related copolymers have been synthesized in presence of toxic and flammable organic solvents but no report is available to synthesize the proposed MPCs through infusing iron oxide nanoparticles (IONs) into poly vinyl pyrrolidone through free radical polymerization of N-vinyl-2- pyrrolidone (NVP) under MW irradiation[14-17]. Herein, we have reported the MW assisted free radical polymerization of NVP in presence of IONs stabilized into a non-ionic surfactant, T-20.Known that, IONs accelerate the polymerization reactions under MW irradiation due to localized heating[18-19].The chemical structure, morphology, thermal, and magnetic characteristics of nanomagnetic polymer composites (MPCs) have been investigated. The effect of MW heating on the yield of the MPCs has also been studied. 


\section{Experimental Part}

\subsection{Materials}

N-vinyl -2-pyrrolidone (NVP, $>98 \%$; Acros) was purified by distillation under reduced pressure and stored at $4^{\circ} \mathrm{C}$ prior to use. 2, 2'-Azobisisobutyronitrile (AIBN, Himedia, India) was used as received without further treatment. $\mathrm{FeCl}_{2} .4 \mathrm{H}_{2} \mathrm{O}$ and solvents were purchased from Sd. Fine Chemicals India. IONs were synthesized through alkaline precipitation method described earlier[20].

\subsection{Synthesis of MPCs under MW Irradiation}

The synthesis of MPCs has been executed into two steps. Initially, a stable dispersion of IONs $(50 \mathrm{mg})$ was prepared in a non ionic surfactant (T-20) under sonication. Afterwards, NVP $\left(9.40 \times 10^{-3} \mathrm{~mol}\right)$ and AIBN $\left(0.61 \times 10^{-3} \mathrm{~mol}\right)$ were added to it. The contents were further sonicated for $10 \mathrm{~min}$. The resulting composition was irradiated at $25-100 \mathrm{~W}$ power over $20 \mathrm{~min}$ in a domestic MW oven $(2.45 \mathrm{GHz})$ operating at four different powers: 25, 50, 75 and $100 \mathrm{~W}$. The synthesized MPCs were isolated. PVP was synthesized under identical reaction conditions in the absence of IONs and served as a control.

\subsection{Characterization}

The percentage yield (Y, \%) of the samples has been evaluated through differential weighing method, subtracting the mass of the AIBN, IONs and T-20. FT-IR (KBr) spectra of samples were recorded on Galaxy 300 Mattson FT-IR infrared spectrometer. ${ }^{1} \mathrm{H}$ NMR spectrum was recorded in $\mathrm{CDCl}_{3}$ over Bruker $400 \mathrm{MHz}$ spectrometer using tetramethylsilane as an internal standard. Crystallographic behaviour of samples was recorded at $25^{\circ} \mathrm{C}$ over $\mathrm{Ri}$ gaku-Geigerflex X-Ray diffractometer using $\mathrm{Cu}-\mathrm{K} \alpha$ radiation $(\lambda=0.154056 \mathrm{~nm})$ at $40 \mathrm{KV}, 20 \mathrm{~mA}$, step size $0.019^{\circ}$ at $9.6 \mathrm{~s}^{-1}$ with $2 \theta$ ranging $20^{\circ}-70^{\circ}$. The SEM of gold coated MPCs was recorded over LEO-6610 at accelerating voltage of $30 \mathrm{kV}$. The samples were prepared in acetone under sonication. Magnetic properties and IONs content were investigated at room temperature using a vibrating sample magnetometer (VSM) Princeton EG\&G Applied Research, model 155 with maximum current $22.5 \mathrm{~A}$ at $900 \mathrm{~s}^{-1}$.Thermal stability of samples (size 10.50-10.73 mg) was studied with reference to alumina powder over Perkin Elmer Pyris Diamond TA in air $(200 \mathrm{~mL} / \mathrm{min})$ up to $800{ }^{\circ} \mathrm{C}$ at the heating rate of $10{ }^{\circ} \mathrm{C} / \mathrm{min}$.

\section{Results and Discussion}

\subsection{Effect of MW Power}

Free radical polymerization of NVP at $25-100 \mathrm{~W}$ has afforded PVP with Y (\%) ranging 74.0-16.3.On contrary; the same polymerization reaction in presence of IONs has provided the relatively better Y (\%) ranging 99.9-40.7.In either case, maximum value for Y (\%) was reported at $25 \mathrm{~W}$. Fur- ther increase in MW wattage favours the mass loss, assuming the MW assisted degradation of the polymers from the MPCs[21].The dispersion of IONs into reaction mixture has enhanced the Y (\%) by 25.9 due to the localized inductive heating[Table.1].

Table.1. Effect of MW Power on Polymerization Reaction

\begin{tabular}{ccc}
\hline \multirow{2}{*}{ MW power (W) } & \multicolumn{2}{c}{ Yield (\%) } \\
\cline { 2 - 3 } & PVP & MPCs \\
25 & 74.0 & 99.9 \\
50 & 70.1 & 88.4 \\
75 & 40.3 & 67.2 \\
100 & 16.3 & 40.7 \\
\hline
\end{tabular}

\subsection{Microstructure}

XRD pattern of IONs have revealed the characteristic

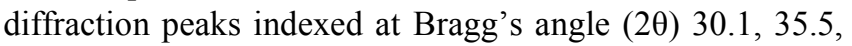
43.3, 57.1 and 62.7 with corresponding $h k l$ values (220), (311), (400), (422 and 511), and (440) respectively. The experimental basal spacing results were in close agreement with ASTM data of $\mathrm{Fe}_{3} \mathrm{O}_{4}$. The calculation based upon Debye-Scherrer equation has provided the crystallite size of IONs 18.2 nm[20][Fig.1.1]. The XRD patterns of neat PVP and MPCs are shown in Fig. 1.2.

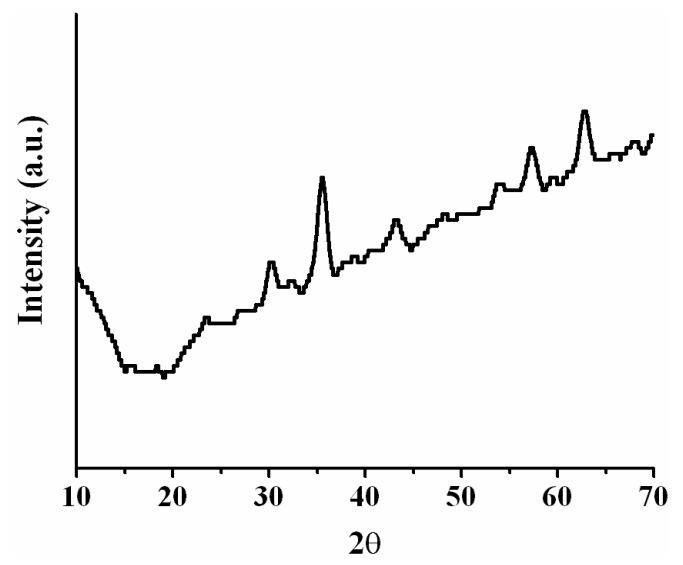

Figure 1.1. XRD pattern of IONs

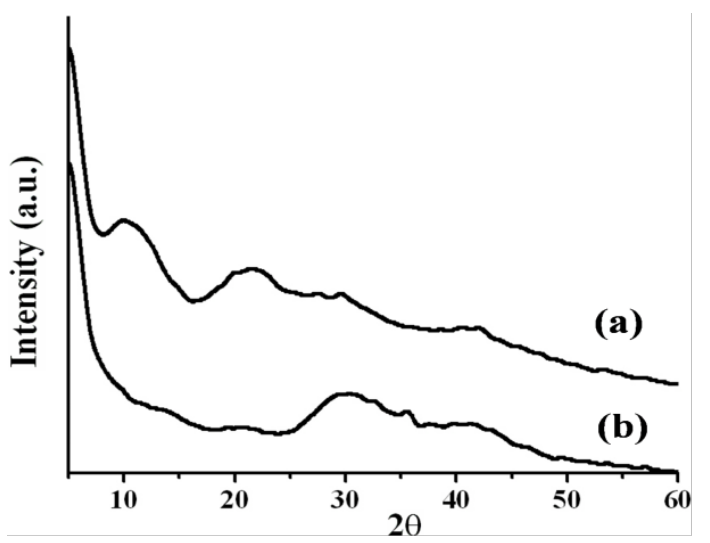

Figure 1.2. XRD pattern of PVP (a) and MPCs (b)

The broad peak at $11.695^{\circ}\left(\mathrm{d}=7.56057 \mathrm{~A}^{0}\right)$ marks the amorphous character of PVP. XRD pattern of MPCs represents diffused peaks of very low intensity at $30.2^{\circ}$ and $35.5^{\circ}$ corresponding to the IONs. These results assure that 
the PVP adsorbed onto the IONs and has strong interaction with the particles which is further determined through microscopy.
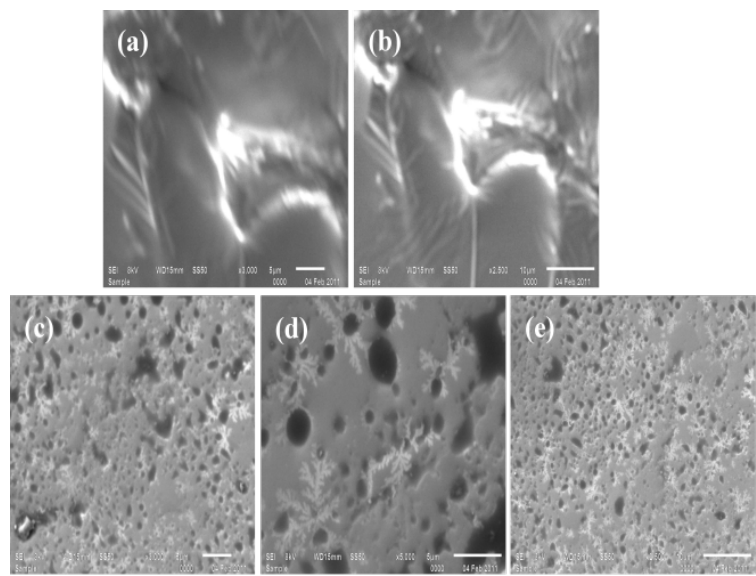

Figure 2. SEM Images of PVP (a) and (b), MPCs (c), (d) and (e) scanned at $5 \mu \mathrm{m}$ and $10 \mu \mathrm{m}$

Fig.2 shows the SEM micrographs of PVP and MPCs. Interestingly, SEM images displayed that nanosized IONs are visible as dark spots inside the branched polymeric shell. SEM images revealed a growth of macromolecular chain over the surface of IONs, imparting heterogeneous morphology of MPCs.

\subsection{Spectra}

The IR spectrum of IONs has revealed the characteristic wavenumber $\left(\mathrm{cm}^{-1}\right)$ at $583.26\left(\mathrm{Fe}-\mathrm{O}, \mathrm{M}-\mathrm{O}_{\text {tetra }}\right) 434.78-418.53$ (Fe-O, M-O $\left.{ }_{\text {octa }}\right)\left[\right.$ Fig.3a]. PVP shows wavenumber $\left(\mathrm{cm}^{-1}\right)$ at $3446.68(v \mathrm{O}-\mathrm{H}), 2924.72\left(v \mathrm{C}-\mathrm{H}_{\text {assym }}\right), 1657.98(v \mathrm{C}=\mathrm{O})$, 1462.25-1369.57 ( $\mathrm{C}-\mathrm{H}$, cyclic deformation of cyclic $\left.\mathrm{CH}_{2}\right)$, 1288.48-1104.38 ( $v$ C-N, $3^{\circ}$ amide)[Fig.3b]. MPCs has revealed wavenumber $\left(\mathrm{cm}^{-1}\right)$ at $3431.16(\mathrm{v} \mathrm{O}-\mathrm{H}), 2956.18(\mathrm{v}$ $\left.\mathrm{C}-\mathrm{H}_{\text {assym. }}\right), 1659.98(v \mathrm{C}=\mathrm{O}), 1469.57-1374.06(\delta \mathrm{C}-\mathrm{H}$; cyclic deformation of cyclic $\left.\mathrm{CH}_{2}\right), 1289.47$ ( $v \mathrm{C}-\mathrm{N}, 3^{\circ}$ amide), $573.91(v \mathrm{Fe}-\mathrm{O})$. The encapsulation of PVP onto the IONs has induced a band shift due to the interaction between the PVP and the metal ions[Fig.3c].

${ }^{1} \mathrm{H} \mathrm{NMR}\left(\mathrm{CDCl}_{3}\right)$ has revealed the characteristic chemical shifts, $\delta_{\mathrm{ppm}}=1.30\left(-\mathrm{C}_{2}\right.$ vinyl $), 1.60-1.90\left(-\mathrm{C}_{2}\right.$ (ring) of PVP), $2.70\left(-\mathrm{CH}_{2 \text { (ring) }}\right.$ adjacent to $\left.\mathrm{C}=\mathrm{O}\right), 3.19\left(-\mathrm{CH}_{2}\right.$ (ring) adjacent to $\mathrm{N})$ corresponded to the methylene in the ring of PVP and 3.70 ( $-\mathrm{C} \underline{\mathrm{H}}$ attached to $\mathrm{N}$ atom of pyrrolidone)[Fig.4].

\subsection{Thermal Stability}

TG-DTA-DTG investigation of the samples was performed to study their thermal stability. The temperatures at which the maximum weight losses were occurring are presented in Fig.5.The thermal decomposition of PVP starts at near $142^{\circ} \mathrm{C}$ and a sharp burning of polymer chains in pure PVP sample occurs between 375 and $461{ }^{\circ} \mathrm{C}$ with weight loss of $\sim 7 \%$ of the initial sample weight. A well defined DTG peak $\left(\mathrm{T}_{\max }\right)$ centered at $438^{\circ} \mathrm{C}$ is observed with an exothermic signal at $489^{\circ} \mathrm{C}$. Final degradation stage is visible at $559^{\circ} \mathrm{C}$ and the total mass loss approaches near to zero. In contrast, thermal degradation of MPCs was established at $175^{\circ} \mathrm{C}$, but a steep weight loss was reported at $261{ }^{\circ} \mathrm{C}-450$ ${ }^{\circ} \mathrm{C}(\sim 76 \%)$. No further weight loss was observed up to $800{ }^{\circ} \mathrm{C}$. Prior to $175^{\circ} \mathrm{C}$, the minor weight loss was related to the loss of impurities $\left(\mathrm{H}_{2} \mathrm{O}\right.$, atmospheric $\mathrm{CO}_{2}$ and residual monomer $)$ whereas, the major weight loss was due to the combustion of organic PVP matrix. On the DTA curve, main exothermic peaks were observed at 272 and $436{ }^{\circ} \mathrm{C}$, suggesting the thermal events related to the decomposition of untreated $\mathrm{Fe}$ (II) chloride along with the degradation of PVP by dehydration of the polymer side chain, which was confirmed by a dramatic weight loss in TG curve at the corresponding temperature range $\left(261-450{ }^{\circ} \mathrm{C}\right)$. The decomposition of MPCs was almost complete around $550{ }^{\circ} \mathrm{C}$, and about 0.6 of residual mass was present at this final temperature. The comparative of thermal behaviour concludes that the presence of IONs into PVP matrix does not impart significant thermal stability to the resulting MPCs. An early onset of thermal decomposition of MPCs has been investigated in presence of IONs, but overall weight loss was remarkably reduced[22].

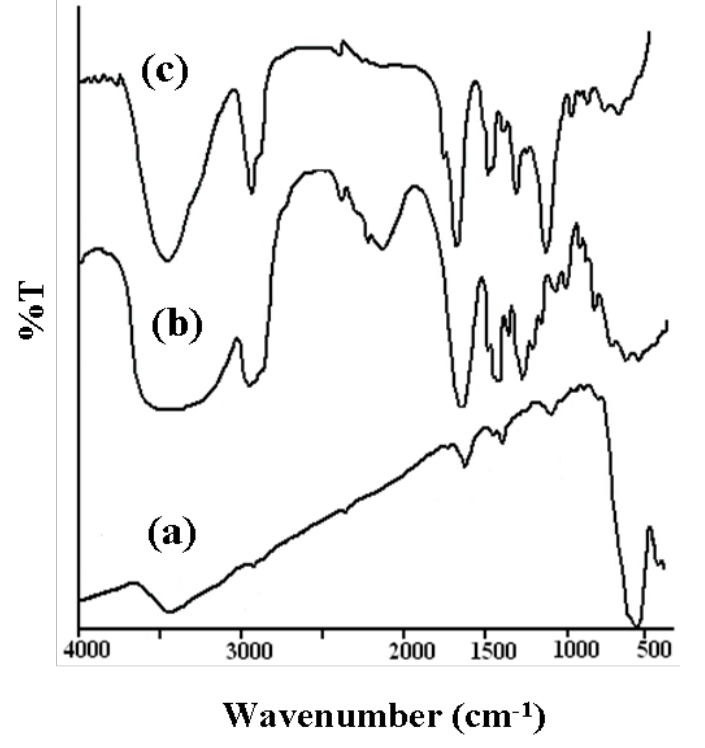

Figure 3. FT-IR Spectra of IONs (a), PVP (b) and MPCs(c)

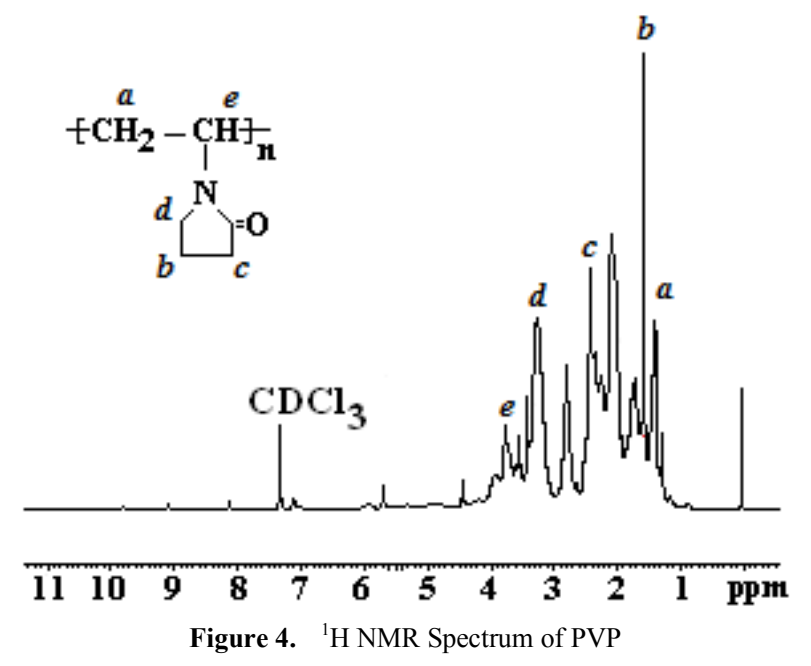



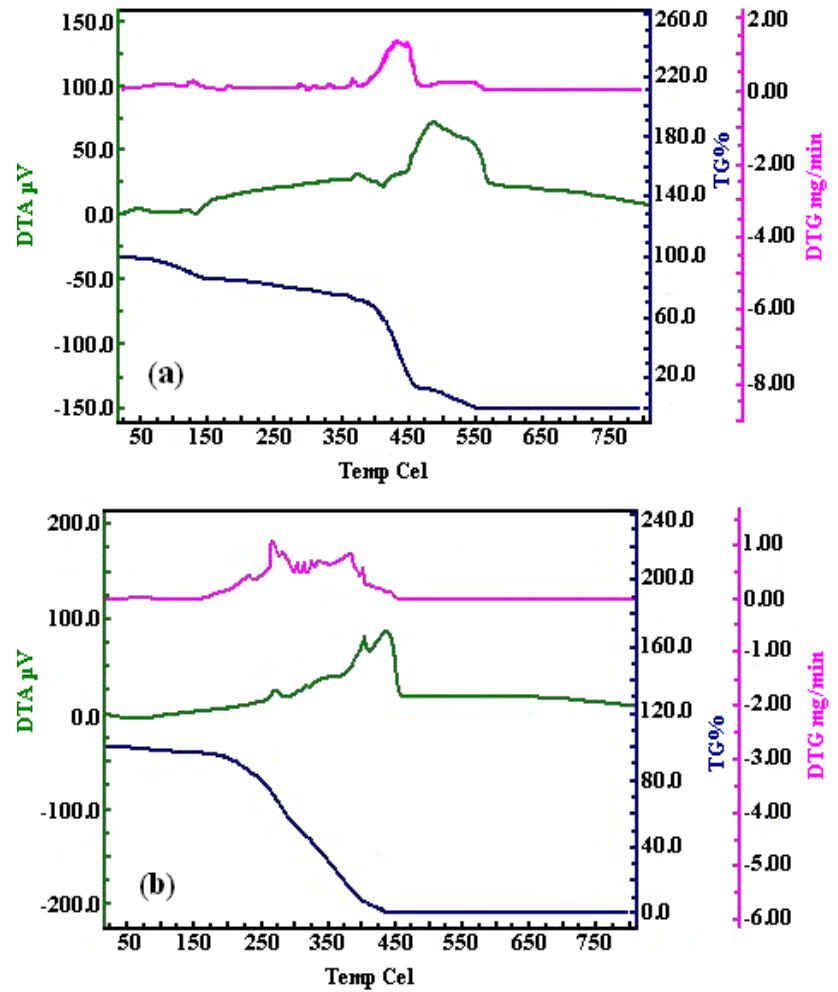

Figure 5. TG-DTA-DTG of PVP (a) and (b) MPCs

\subsection{Magnetic Properties}

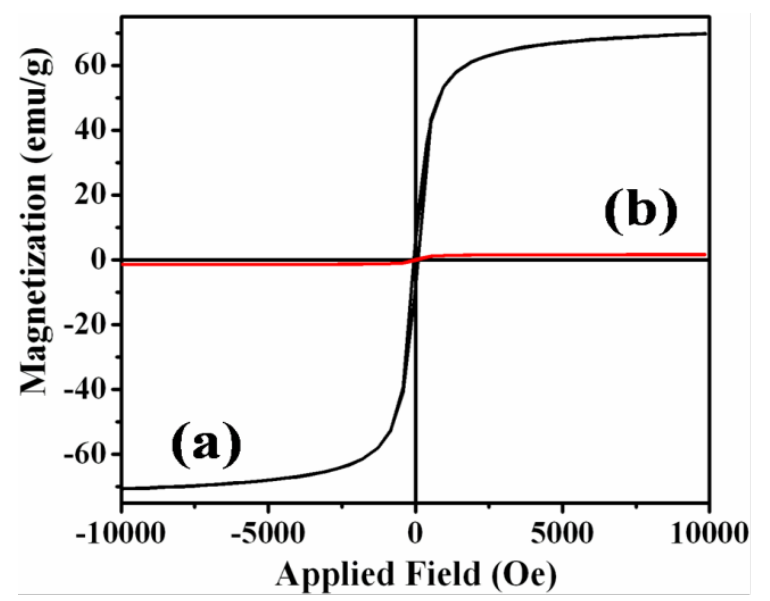

Figure 6. M-H curve of IONs (a) and MPCs (b) studied through VSM

The magnetic characteristics of IONs and MPCs are obtained by measuring their $\mathrm{M}-\mathrm{H}$ loops in the applied field ranging $-10 \mathrm{kOe}$ to $10 \mathrm{kOe}$ at room temperature[Fig.6]. M-H curve of IONs has revealed saturation magnetization $\left(\mathrm{M}_{\mathrm{s}}\right)$ $70.0 \mathrm{emu} / \mathrm{g}$ with squareness $\mathrm{M}_{\mathrm{r}} / \mathrm{M}_{\mathrm{s}}(0.073)$ indicating an appreciable fraction of superparamagnetic particles. However, the magnetism of MPCs was not perfect and it was decreased to $1.961 \mathrm{emu} / \mathrm{g}$ with $\mathrm{M}_{\mathrm{r}} / \mathrm{M}_{\mathrm{s}}(0.139)$ due to oxidation during polymerization and the thickness of the polymer shell might also affect the magnetism of the MPCs. VSM data has provided $2.80 \%$ IONs content of MPCs[23].

\section{Conclusions}

MW assisted free radical polymerization of $\mathrm{N}$-vinyl -2-pyrrolidone (NVP) in presence of T-20 stabilized IONs has been conducted successfully at MW power ranging $25-100 \mathrm{~W}$. With MW power, the polymerization reaction was progressed resulting in the development of iron oxide filled polyvinyl pyrrolidone nanocomposites (MPCs) with higher yield over neat PVP. Formation of MPCs has been ascertained through FT-IR, XRD and SEM. The insertion of IONs into PVP matrix has no remarkable effect on thermal stability of MPCs. The assessed magnetic properties revealed that, the synthesized MPCs may be used for the development of sensor and data storage devices. The proposed MW assisted route offers an efficient, faster, cleaner and economic alternative heating source to synthesize the nanocomposites.

\section{ACKNOWLEDGEMENTS}

The financial assistance granted by Department of Biotechnology, Ministry of Science \& Technology, India is duly acknowledged. The authors are also grateful to Institute Instrumentation Centre, IIT Roorkee, India.

\section{REFERENCES}

[1] Hamidi, M., Azadi, A. and Rafiei, P., 2008, Hydrogel Nanoparticles in Drug Delivery, Advanced Drug Delivery Reviews, 60, 1638-1649.

[2] Oh, J. K. and Park J.M., 2011, Iron Oxide-Based Superparamagnetic Polymeric Nanomaterials: Design, Preparation, and Biomedical Application, Progress in Polymer Science 36,168-189.

[3] Dong, X., Zheng, Y., Huang, Y., Chen, X. and Jing, X., 2010, Synthesis and Characterization of Multifunctional Poly (Glycidyl Methacrylate) Microspheres and Their Use in Cell Separation, Analytical Biochemistry, 405, 207-212.

[4] Neves, J. S. Souza, F. G. Suarez, P. A. Z.; Umpierre, A. P. and Machado, F., 2011, In situ Production of Polystyrene Magnetic Nanocomposites through a Batch Suspension Polymerization Process, Macromolecular Materials and Engineering, DOI:10.1002/mame.201100050.

[5] Garcia, I., Zafeiropoulos, N. E., Janke, A. , Tercjak, A.; Eceiza, A., Stamm, M. and Mondragon, I., 2007, Functionalization of Iron Oxide Magnetic Nanoparticles with Poly(Methyl Methacrylate) Brushes via Grafting-From Atom Transfer Radical Polymerization, Journal of Polymer Science Part A: Polymer Chemistry, 45(5),925-932.

[6] Lan, F., Liu, K.X., Jiang, W., Zeng, X.B.,Wu, Y. and Gu, Z.W., 2011.Facile Synthesis of Monodisperse Superparamagnetic $\mathrm{Fe}_{3} \mathrm{O}_{4} /$ PMMA Composite Nanospheres with High Magnetization, Nanotechnology. 22,225604 DOI: $10.1088 / 0957-4484 / 22 / 22 / 225604$.

[7] Chen, X., Wei, S., Gunesoglu, C., Zhu, J., Southworth, C. S., Sun, L., Karki, A. B. ,Young, D.P. and Guo, Z., 2010 , Electrospun Magnetic Fibrillar Polystyrene Nanocomposites Reinforced with Nickel Nanoparticles, Macromolecular 
Chemistry and Physics, 211(16),1775-1783.

[8] Liao, L., Zhang, C. and Gong, S., 2007, Microwave-Assisted Synthesis and Characterization of Poly ( $\varepsilon$-Caprolactone)/Montmorillonite Nanocomposites, Macromolecular Chemistry and Physics, 208(12), 1301-1309.

[9] Gotelli, G. A., Bonelli, P., Abraham, G. A. and Sosnik, A., 2011, Fast and Efficient Synthesis of High Molecular Weight Poly ( $\varepsilon$-Caprolactone) Diols by Microwave-Assisted Polymer Synthesis. Journal of Applied Polymer Science, 121, 1321-1329.

[10] Hong, R.Y., Pan, T.T. and Li, H.Z., 2006 , Microwave Synthesis of Magnetic $\mathrm{Fe}_{3} \mathrm{O}_{4}$ Nanoparticles Used As A Precursor of Nanocomposites and Ferrofluids, Journal of Magenetism and Magnetic Materials, 303(1), 60-68.

[11] Huang, J., Pen, H., Xu, Z. and Yi, C., 2008, Magnetic $\mathrm{Fe}_{3} \mathrm{O}_{4}$ /Poly (Styrene-co-Acrylamide) Composite Nanoparticles Prepared by Microwave-Assisted Emulsion Polymerization, Reactive and Functional Polymers, 68,332-339.

[12] Zhang, Z., Zhang, Y., Tan, W., Li, G., and Hu, Y., 2010 , Preparation of Styrene-co-4-Vinylpyridine Magnetic Polymer Beads by Microwave Irradiation for Analysis of Trace 24-Epibrassinolide in Plant Samples Using High Performance Liquid Chromatography, Journal of Chromatography A, 1217, 455-6461.

[13] Galiev, E. E. S. , Stakhanov, A. I. , Blagodatskikh, I. V., Kobitskaya, E. M., Khokhlov, A. R., Naumkin, A. V., Volkov, I. O., Volkov, V. V., Shtykova, E. V., Dembo, K. A. and Pisarev, S. A., 2010,Synthesis of Polyvinylpyrrolidone and its Nanosilver Based Polymer Composites in Supercritical Carbon Dioxide. Polymer Science Series B, 52(3-4), 165-173.

[14] Sangmanee, M. and Maensiri, S., 2009, Nanostructures and Magnetic Properties of Cobalt Ferrite $\left(\mathrm{CoFe}_{2} \mathrm{O}_{4}\right)$ Fabricated by Electrospinning, Applied Physics A, 97, 167-177.

[15] Lu, X.Y., Niu, M., Yang, C., Yi, L., Qiao, R., Du, M.H. and Gao, M., 2010, One-Pot Synthesis of PVP-Coated
$\mathrm{Ni}_{0.6} \mathrm{Fe}_{2.4} \mathrm{O}_{4}$ Nanocrystals, Chinese Science Bulletin, 55(30), 3472-3478.

[16] Baykal, A, Bitrak, N. Ünal, B., Kavas, H. Durmus, Z. , Özden, Ş. and Toprak, M.S.,2010, Polyol Synthesis of (Polyvinylpyrrolidone) $\mathrm{Pvp}-\mathrm{Mn}_{3} \mathrm{O}_{4}$ Nanocomposite, Journal of Alloys and Compounds, 502(1),199-205.

[17] Miyauchi, M., Simmons, T, J., Miao, J., Gagner, J. E., Shriver, Z, H., Aich, U., Dordick, J. S. and Linhardt, R.J., 2011, Electrospun Polyvinylpyrrolidone Fibers with High Concentrations of Ferromagnetic and Superparamagnetic Nanoparticles, ACS Applied Materials Interfaces, 3, 1958-1964.

[18] Klink, M., Kolb, U. and Ritter, H., 2005, Microwave-Assisted Synthesis of Channel-Containing Polymeric Materials, e-Polymer, 069, 1-6.

[19] Arellano, C. G., Campelo, J.M., Macquarrie, D. J., Marinas, J. M., Romero, A.A. and Luque, R., 2008, Efficient Microwave Oxidation of Alcohols Using Low-Loaded Supported Metallic Iron Nanoparticles, Chemsuschem, 1(8-9), 746-750.

[20] Zaidi, M. G. H., Sah, P. L., Alam, S. and Rai, A. K., 2009, Synthesis of Epoxy Ferrite Nanocomposites in Supercritical Carbon Dioxide. Journal of Experimental Nanoscience, 4(1), 55-66.

[21] Singh, V., Tiwari, A., Kumari, P. and Sharma, A.K., 2007, Microwave Accelerated Synthesis and Characterization of Poly (Acrylamide), Journal of Applied Polymer Science, 104 (6), 3702-3707.

[22] Silva, M. F., Silva, C. A., Fogo, F. C., Pineda, E. A. G. and Hechenleitner, A. A. W. ,2005, Thermal and FTIR Study of Polyvinylpyrrolidone/Lignin Blends, Journal of Thermal Analysis and Calorimetry, 79, 367-370.

[23] Gong, T., Yang, D., Hu, J., Yang, W., Wang, C., Lu, J.Q., 2009, Preparation of Monodispersed Hybrid Nanospheres with High Magnetite Content from Uniform $\mathrm{Fe}_{3} \mathrm{O}_{4}$ Clusters, Colloids and Surfaces A: Physicochem. Eng. Aspects, 339, 232-239. 